\title{
A Note on XXII International Society for Photogrammetry and Remote Sensing Congress,
} Melbourne 2012, Australia - K.S. Jayappa and Vipin Joseph Markose, Department of Marine Geology, Mangalore University, Mangalagangotri - 574199 (Email: ksjayappa@yahoo.com)

The XXII ISPRS Congress was held at Melbourne Convention and Exhibition Centre, Australia from 25 August to 1 September 2012. 'Imaging a Sustainable Future' was the focal theme and various other themes of the Congress were Geomatics; Disaster Management; Global Land Cover Mapping; Radar Remote Sensing; Dynamics of GIS; Climate Change, Future's Earth Surface Processes; Small Satellite Status, Opportunities and Challenges; Developments in Computer Vision; and Photogrammetry. The Congress consisted of plenary, invited, short interactive and oral presentations. A few plenary talks given are as follows: Piero Boccardo (ITHACA-Politecnico di Torino, Italy) gave a talk on the different aspects of disaster management and early warning systems devoted to flood and drought. Rainer Sandau from German Aerospace Center made an interesting presentation on small satellites status, opportunities, challenges and missions. Ranganath Navalgund, former Director of Space Application Centre, ISRO, Ahmedabad, delivered on 'Earth Observation for Early Warning System'. His lecture covered the role played by earth observation satellites in disaster monitoring and mitigation; identify gaps in technology and understanding of additional efforts required in the area of early warning for different types of disasters. Madhu Chandra, Chemnitz University of Technology,
Germany highlighted the applications of radar remote sensing in the areas of earth observation and disaster management. Peng Gong from the Institute for Global Change Studies, China spoke on 'new image classification algorithms including traditional statistical algorithms, new generation machine learning algorithms and hierarchical land cover classification approach'. Stuart Lane, Institut de géographie, Faculté des géosciences et l'environnement, Université de Lausanne, Switzerland explained the role of terrain measurements in earth surface processes and landscapes.

About fifteen researchers from India participated in the congress and made presentations. P.L.R. Raju, IIRS, Dehradun gave a talk on the role of satellite based education and training with the example of India's EDUSAT programme. Srinivas Kumar (INCOIS) chaired two sessions on 'mass movement' and 'wetland ecosystems'. Pattabhi Rama Rao (INCOIS) spoke about the development of open-source architecture for real-time data reception from the coastal observation network. S. Mohamed Ghouse (Anna University) presented on the use of Cartosat and Resourcesat LISS 4 MSS merged data for delineation, codification of drainage basin and environmental health problems. Bharat Lohani, IIT Kanpur, highlighted on experimental and non-parametric statistical data analysis for displaying the basic terrain features using
LiDAR data. Anjana Vyas, CEPT University, Ahmedabad focused on the issues and challenges in web based education with specific emphasis on the streams of space science and geomatics. K.S. Jayappa (Mangalore Univ.) presented on the application of digital elevation models for identification of neotectonic activity of the Pre-Cambrian terrains of southern India. R.R. Hermon and V. Madhava Rao (Nat. Inst. Rural Development) spoke on the impact assessment of watershed with special emphasis on temporal changes of vegetations in desert regions of Rajasthan. Vijaya Musande, Jawaharlal Nehru Engineering College, Aurangabad, presented on the use of multi-spectral, time series data and fuzzy based classifier to identify the specific crops. Nandini Ray Chaudhury, SAC, Ahmedabad, highlighted the application of hyper-spectral data to spectrally characterize selected corals from Gulf of Kachchh. Sulochana Shekhar, CUK, Gulbarga explained about the methodology of detection of slums using high resolution Quick Bird satellite data. Rakesh Patel (DAIICT, Gandhinagar), explained the novel approach for super-resolution of hyper-spectral images using compressive sensing and its advantages.

The General Assembly at the XXII ISPRS Congress in Melbourne elected Prague as the host for the XXIII Congress to be held in 2016. 